\title{
Severe drought has lasting effects on Amazon
}

\section{Satellite data reveal effects of climate change on tropical forests.}

\section{Hannah Hoag}

\section{December 2012}

A study published today in the Proceedings of the National Academy of Sciences ${ }^{1}$ sheds light on the long-term effects of drought on the Amazon rainforest — giving clues about how the rainforest might be affected by global warming in the future. The researchers report that the severe drought that hit the rainforest in 2005 had lasting effects on the forest canopy, such that it remained damaged at least four years later.

The effects of the 2005 drought have been debated since 2007, when researchers reported in Science ${ }^{2}$ that photosynthesis within the canopy had increased, leading the Amazon basin to 'green up' during the dry period. But in 2010 another group reported that they were unable to reproduce the results using the same data ${ }^{3}$.

"The 'green-up' is a short-term response and a bit of a red herring," says Oliver Phillips, a tropical ecologist at the University of Leeds, UK. But the latest study "transcends that debate", he says. "The question of the underlying health of the forest is much deeper than the instantaneous response."

\section{Bare branches}

A drawback of the method used in the earlier studies - which used satellite measurements to estimate forest greenness using reflected solar radiation - is that the data can be muddied by clouds and atmospheric aerosols. So for the latest study, Sassan Saatchi, a remote-sensing expert at the California Institute of Technology Jet Propulsion Laboratory in Pasadena, California, studied the forest's microwave 'silhouette', showing its contours instead of its greenness. To look at canopy structure, he and his colleagues used microwave satellite data, which are unaffected by clouds, from a NASA probe. When it passed over lush canopy, the satellite sensor recorded a smooth signal. Bare branches, thinned leaves and missing trees showed more roughness.

The researchers found that more than 70 million hectares of rainforest in the western Amazon — an area nearly twice the size of California - were hit by the drought. And the canopy's recovery dragged on long after the drought ended, with its biomass and fullness still below pre-drought levels in 2009 when the satellite suffered a mechanical failure. In 2010, an even stronger drought hit a larger swathe of the Amazon 4 .

\section{Bad timing}

"This is the first piece of really strong evidence that the drought has had a negative impact on the forest," says Greg Asner, an environmental scientist at the Carnegie Institution for Science in Stanford, California.

The latest analysis paints a grim picture for Amazonian rainforests should severe droughts become more frequent. Most Amazonian droughts are driven by warmer surface waters in the eastern Pacific Ocean, but the severe droughts of 2005 and 2010 seem to have been influenced by warmer sea-surface temperatures in the North Atlantic Ocean.

It could change the drought outlook in the next report from the Intergovernmental Panel on Climate Change, due in 2014. The most recent report, released in 2007 and based on climate-modelling experiments done before the droughts, was more "speculative", says Ranga Myneni, an expert in the remote sensing of vegetation at Boston University in Massachusetts, and a co-author on the latest study.

Saatchi says that he hopes to extend the analysis past the 2010 drought using data from the Indian satellite Oceansat-2. If the droughts continue to occur every 5-10 years, the forest edges could begin to transition to dry forests, he warns. "We'd like to say something about how the Amazonian forest has been doing since 2009," he says. 
Nature | doi:10.1038/nature.2012.12129

\section{References}

1. Saatchi, S. et al. Proc. Natl. Acad. Sci. USA http://dx.doi.org/10.1073/pnas.1204651110 (2012).

2. Saleska, S. R., Didan, K., Huete, A. R. \& da Rocha, H. R. Science 318, 612 (2007).

3. Samanta, A. et al. Geophys. Res. Lett. 37, L05401 (2010).

4. Xu, L. et al. Geophys. Res. Lett. 38, L07402 (2011). 